\title{
Situação Epidemiológica da Leishmanise Visceral no Estado de Alagoas - 2002
}

\author{
Dayse Mércia Cavalcante de Oliveira ${ }^{1}$ e Valéria Montoni ${ }^{2}$
}

\section{INTRODUÇÃO}

A área endêmica da Leishmaniose visceral em Alagoas é composta por 66 municípios, persistindo as maiores ocorrências na zona rural do agreste, sertão e litoral. 0 total de casos confirmados no Estado em 2002 representa um coeficiente de incidência de 3,81 por 100.000 habitantes. Observa-se com isso um declínio acentuado em relação ao $\mathrm{n}^{\circ}$ de casos quando comparado ao ano de 2001. No entanto, a situação é grave, tendo em vista a taxa de letalidade de 6\% (8 óbitos para 134 casos confirmados) superior a 2001, que foi de 2,75\% (8 óbitos para 291 casos confirmados), dados visualizados na figura 1 .

\section{METODOLOGIA}

Foi realizada uma avaliação detalhada do banco de dados no SINANW, referente à leishmaniose visceral em Alagoas, no ano de 2002, utilizando o relatório de conferência e o TABWIN.

\section{RESULTADOS}

Dentre os 102 municípios existentes no Estado, 44 registraram casos confirmados de $\mathrm{LV}$, correspondendo a $43,13 \%$.
Na figura 2, observa-se a situação dos municípios de acordo com sua estratificação epidemiológica. Nenhum município foi caracterizado no estrato I. Foram notificados 200 casos no período de janeiro a dezembro, sendo confirmados 134 $(67,0 \%)$, descartados $47(23,5 \%)$ e em investigação 19 $(9,5 \%)$, representando os casos cuja classificação final encontra-se sem preenchimento na ficha individual de investigação. Dessa forma, a proporção de encerramento dos casos notificados foi de 90,5\%. 0 Hospital Escola Hélvio Auto, como hospital de referência realizou $78 \%$ dos atendimentos. A maior proporção de casos confirmados foi no sexo masculino (53\%). A faixa etária de 1 a 4 anos foi a mais acometida (30,6\%), embora a distribuição dos casos confirmados tenha atingido todas as faixas etárias estudadas. Dentre os casos confirmados, o principal tipo de diagnóstico foi o de exames complementares representando 60\% (80 casos), dos quais 57 tiveram o exame parasitológico direto positivo. A proporção de casos confirmados que evoluíram para cura foi de $54 \%$, e para óbito $6 \%$. Essa informação refere-se ao total de fichas individuais de investigação, onde a variável evolução encontra-se preenchida. Quanto aos "outros", foram considerados todos os casos sem registro de alta por cura, incluindo os ignorados e os não classificados.

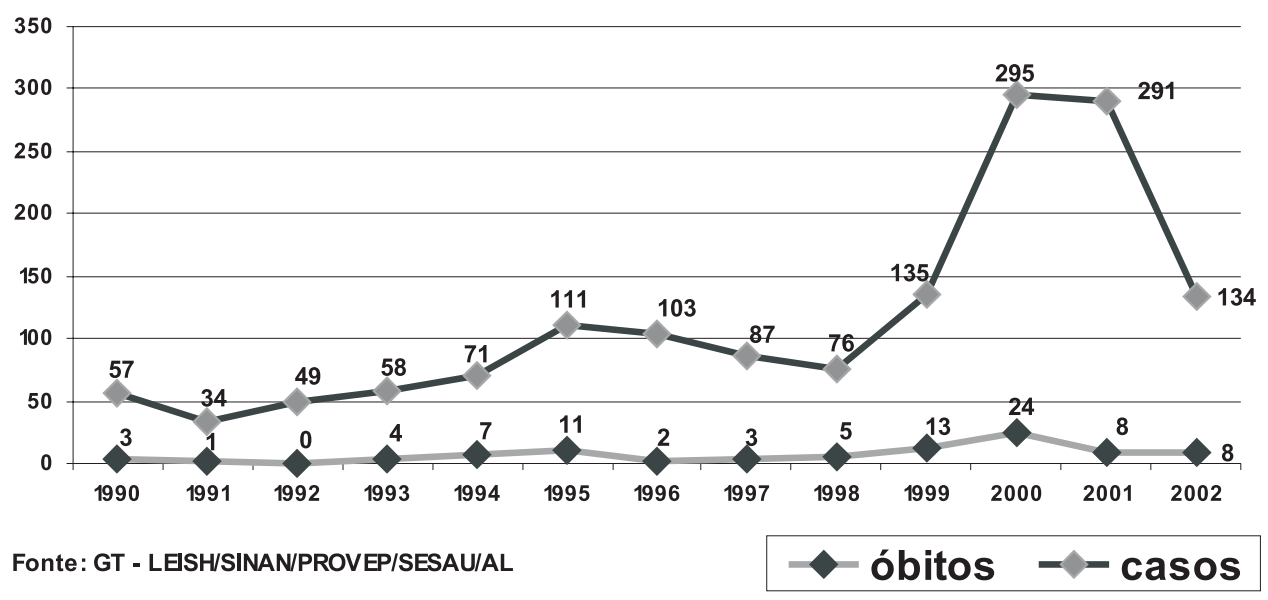

Figura 1 - Leishmaniose visceral, casos confirmados e óbitos, Alagoas, 1990-2002. 


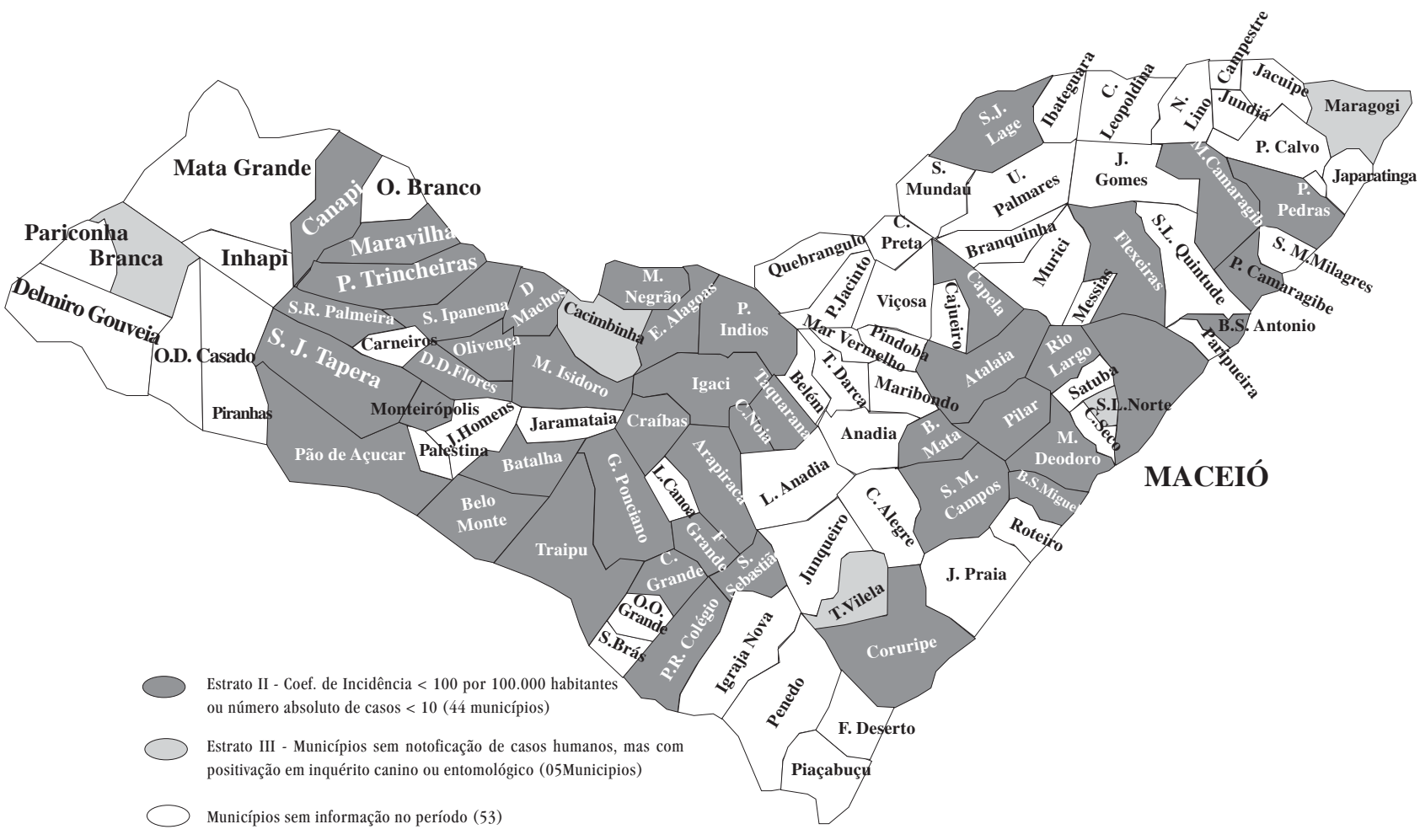

Fonte: GTLV/PROVEP/SESAU

\section{CONCLUSÃo}

Verificou-se que apesar da redução do $\mathrm{n}^{0}$ de casos, a taxa de letalidade em 2002 é significante quando comparada com $o$ ano de 2001.A ocorrência de casos parece não sofrer influência das ações de controle realizadas, exceto em situações de surtos, tendo em vista que no ano avaliado, raros municípios adotaram alguma medida de controle. É preciso investir na intensificação das ações de vigilância epidemiológica e na capacitação dos profissionais de saúde no diagnóstico e tratamento da leishmaniose visceral. 